Abstract P0-0725 c Table 2 Correlations between the liverspleen dimensions and gestational age, height, weight

\begin{tabular}{|c|c|c|c|c|c|c|c|c|}
\hline \multirow{2}{*}{ Maximum } & & \multirow[t]{2}{*}{ Mean } & \multirow[t]{2}{*}{ Median } & \multirow[t]{2}{*}{ Minimum } & \multicolumn{4}{|c|}{ Percentile } \\
\hline & & & & & 5th & 95th & & \\
\hline \multirow[t]{3}{*}{ Liver (mm) } & Longitudinal & $60.9 \pm 4.9$ & 61.0 & 49.0 & 77.0 & & 53.0 & 69 \\
\hline & .7 & & & & & & & \\
\hline & $\begin{array}{l}\text { Anteroposterior } \\
0\end{array}$ & $44.1 \pm 4.5$ & 44.0 & 31.0 & 57.0 & & 38.0 & 52 \\
\hline \multirow[t]{2}{*}{$\begin{array}{l}\text { Spleen } \\
(\mathrm{mm})\end{array}$} & $\begin{array}{l}\text { Longitudinal } \\
.7\end{array}$ & $38.2 \pm 4.3$ & 38.0 & 28.0 & 54.0 & & 32.0 & 45 \\
\hline & $\begin{array}{l}\text { Anteroposterior } \\
0\end{array}$ & $21.7 \pm 2.8$ & 22.0 & 15.0 & 29.0 & & 17.0 & 27 \\
\hline
\end{tabular}

${ }^{* * *}$ Statistically significant at $p<.001{ }^{* *}$ Statistically significant at $p<.01{ }^{*}$ Statistically significant at $p<.05$

0.05). Longitudinal and anteroposterior dimensions of liver and spleen showed no correlation with the gestational age. All dimensions of liver and spleen showed a high correlation with the height and weight. Weight was the best correlated with all dimensions.

Conclusions The reference values of spleen and liver lengths and diagrams from this study may be useful in the sonographic evaluation of spleen and liver in newborns.

\section{P0-0725d RED CELL TRANSFUSION REQUIREMENT IN PRETERM INFANTS OF TWIN OR HIGHER ORDER}

E Cameron, K Swamy, D Batra. Neonatology, Nottingham University Hospitals, Nottingham, UK

\subsection{6/archdischild-2014-307384.1364}

Background Preterm infants often require red cell transfusions (RCT) during their neonatal unit stay. Recently many studies have focussed on reducing the transfusion requirements e.g. delayed cord clamping, cord milking. Majority of these studies do not include the preterm infants that are of twin or higher order. This study was designed to investigate if the transfusion requirements in twins were different from singletons.

Method Retrospective data was collected from patient records for preterm infants below 32 weeks gestation admitted to regional tertiary neonatal unit at Nottingham City Hospital from October 2011 to February 2013. We compared transfusion requirements in singletons versus neonates of twin or higher order. All infants, singletons or twins, received similar neonatal care in terms of nutrition, supplements and thresholds for RCT. Results A total of 113 infants (37 twins group and 76 singleton group) were identified at gestation below 32 weeks. Groups were comparable in terms of weight, sex distribution, haemoglobin at admission and mode of delivery.

$48.6 \%$ of preterm twin and higher order infants required RCT compared to $53.9 \%$ of singleton infants $(p=0.6892)$ and on an average requiring 1 transfusion compared to 1.4 RCT per infant who were singleton. Outcomes at 6 weeks were comparable between the 2 groups.

Conclusion We conclude that preterm twin and higher order infants have comparable RCT requirements to singleton infants. This emphasises the need to focus on strategies to impact on the use of RCT in this population subgroup.

Ackowledgements PD Dr Heike Rabe for her guidance in planning the study.

\section{P0-0725e CEREBRAL TISSUE OXYGENATION AT BIRTH IN TERM INFANTS: COMPARISON BETWEEN EARLY AND LATE CORD CLAMPING}

${ }^{1} \mathrm{~B}$ Arcagok, ${ }^{1} \mathrm{H}$ Bilgen, ${ }^{15} \mathrm{~S}$ Coskun, ${ }^{2} \mathrm{M}$ Guclu, ${ }^{3} \mathrm{D}$ Save, ${ }^{1} \mathrm{~A}$ Memisoglu, ${ }^{4} \mathrm{~K}$ Gucuyener, ${ }^{1}$ E Ozek. ${ }^{1}$ Department of Pediatrics Division of Neonatology, Marmara University Medical Faculty, Istanbul, Turkey; ${ }^{2}$ Department of Obstetrics and Gynecology, Marmara University Medical Faculty, Istanbul, Turkey; ${ }^{3}$ Department of Public Health, Marmara University Medical Faculty, Istanbul, Turkey; ${ }^{4}$ Department of Pediatric Neurology, Gazi University Medical Faculty, Ankara, Turkey

\subsection{6/archdischild-2014-307384.1365}

Background and aims The aim of our study is to compare the postnatal cerebral tissue oxygenation values in babies with early versus late cord clamping born after elective $\mathrm{C} / \mathrm{S}$.

Methods In this prospective, observational study, we included term newborns delivered by elective $\mathrm{C} / \mathrm{S}$. Babies were segregated into two groups as early (within 15 seconds) and late cord clamping (at 60th seconds). Peripheral arterial oxygen saturation $\left(\mathrm{SpO}_{2}\right)$ and heart rate were measured using pulse oximetry (Nellcor N200) and regional oxygen saturation of the brain $\left(\mathrm{rSO}_{2}\right.$ brain) were measured (Invos 5100) between the 3rd and15th minutes and recorded every minute. Fractional tissue oxygen extraction (FTOE) was calculated for each minute $(\mathrm{FTOE}=$ pulse oximetry value-rSO $\mathrm{S}_{2}$ /pulse oximetry value). The measurements were compared for both groups.

Results The demographical characteristics, $\mathrm{SpO}_{2}$ levels, heart rates and umbilical cord blood gas values were not significantly different between the groups $(p>0.05)$. Cerebral oxygenation measurements and FTOE values were significantly higher for each minute in the late cord clamping group $(\mathrm{p}<0.05)$. Bilirubin and hematocrit levels were also statistically higher in this group $(p<0.05)$ without the need for phototherapy. The increase in $\mathrm{rSO}_{2}$ was faster and the $\mathrm{rSO}_{2}$ plateau was reached earlier in the late cord clamping group (Figure).

Conclusions In our study we found that $\mathrm{rSO}_{2}$ brain measurements and FTOE values were higher in the late cord clamping

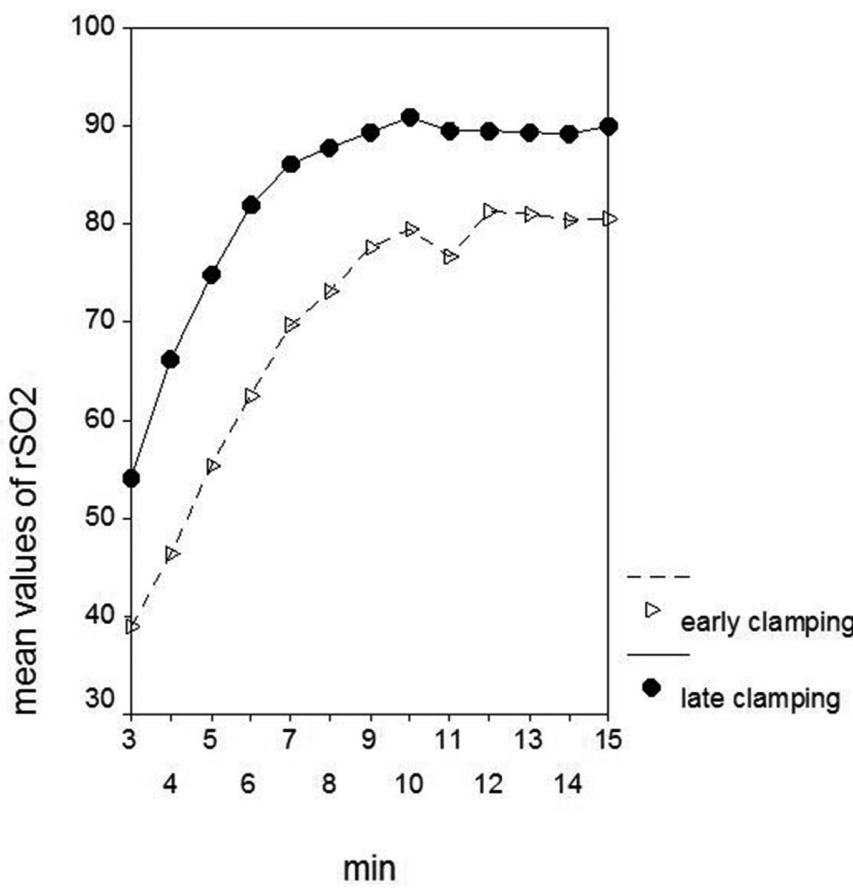

Abstract P0-0725e Figure 1 